\title{
HER2/Neu Status by Validated Dual-probe in Situ Hybridization
}

National Cancer Institute

\section{Source}

National Cancer Institute. HER2/Neu Status by Validated Dual-probe in Situ Hybridization. NCI Thesaurus. Code C156892.

An in situ hybridization assay for HER2/Neu that combines a validated assay for HER2 with a probe for chromosome 17, with the assay performed in a validated testing lab. 